\title{
Stability of a Rigid Rotor Supported on Flexible Oil Journal Bearings
}

Bankim C. Majumdar

Lewis Research Center

Cleveland, Ohio

David E. Brewe

Propulsion Directorate

U.S. Army Aviation Research and Technology Activity-AVSCOM

Lewis Research Center

Cleveland, Ohio

and

Michael M. Khonsari

Ohio State University

Columbus, Ohio

(MASA-TH-89899) STABILITY CF BIGID BOTCR

N87-24646

SUFFCETED ON FLEXIBLE CIL JCUFAAL BEARINGS

(AASA) $29 \mathrm{p}$ AVAII: NIIS EC ACI/ME 01

CSCL 20D $\begin{array}{ll}\text { Unclas } \\ 0080601\end{array}$

Prepared for the

1987 Joint Tribology Conference

cosponsored by the American Society of Lubrication Engineers and the American Society of Mechanical Engineers

San Antonio, Texas, October 5-8, 1987 
STABILITY OF A RIGID ROTOR SUPPORTED ON FLEXIBLE OIL JOURNAL BEARINGS

\author{
Bankim C. Majumdar* \\ National Aeronautics and Space Administration \\ Lewis Research Center \\ Cleveland, ohio 44135 \\ David E. Brewe \\ Propulsion Directorate \\ U.S. Army Aviation Research and Technology Activity - AVSCOM \\ Lewis Research Center \\ Cleveland, Ohio 44135 \\ and \\ Michael M. Khonsari \\ Ohio State University \\ Columbus, Ohio 43210
}

\title{
SUMMARY
}

This investigation deals with the stability characteristics of o11 journal bearings, including the effect of elastic distortions in the bearing liner. Graphical results are presented for (1) steady-state load, (2) stiffness and damping coefficients, and (3) the stability. These results are given for varfous slenderness ratios, eccentricity ratios, and elasticity parameters. The lubricant is first assumed to be isoviscous. The analysis is then extended to the case of a pressure-dependent viscosity. It has been found that stability decreases with increase of the elasticity parameter of the bearing liner for heavily loaded bearings.

\section{NOMENCLATURE}
$a, b$
inside and outside radius of the bearing
B $\quad n_{0} \alpha \omega R^{2} / c^{2}$
C $2+\lambda / \mu$
c radial clearance
D journal diameter

*National Research Council - NASA Research Associate. 
$\overline{\mathrm{D}} r r, \overline{\mathrm{D}} r \varphi$, $\bar{D} \varphi r, \bar{D} \varphi \varphi$

$$
d_{m, n}
$$$$
\text { E }
$$

e

F

G

H

$h, \bar{h}$

1

$\underline{\mathrm{K}} r r, \overline{\mathrm{K}} r \varphi$,

$\bar{K} \varphi r, \bar{K}_{\varphi \varphi}$

L

$M, \bar{M}$

$m, n$

$p, \bar{p}$

$\bar{p}_{0}, \bar{p}_{1}, \bar{p}_{2}$

dimensionless damping coefficients $\left(\bar{D}=D c^{3} / n_{0} R^{3} L\right)$, where the first and second subscripts refer to the component of the force and the direction of the velocity respectively

distortion of the $m, n$ harmonic

Young's modulus

eccentricity

elasticity parameter, $F=n_{0} R^{3} \omega / c^{3} E$

aE

thickness of bearing liner

film thickness, $\bar{n}=h / c$

$\sqrt{-1}$

dimensioniess stiffness coefficients $\left(\bar{K}=K_{c} 3 / n_{0} \omega R^{3} L\right)$, where the first and second subscripts refer to the component of the force and the direction of the displacement respectively

length of bearing

mass of rotor, $\bar{M}$, mass parameter $\left(\bar{M}=M c \omega^{2} / W\right)$

axial and circumferential harmonic

pressure, $\left(\bar{p}=p c^{2} / n_{0} \omega R^{2}\right)$

steady-state and perturbed (dynamic) dimensionless

pressures

$q, \bar{q} \quad$ modified pressure, $\left(\bar{q}=1 / B\left(1-e^{-\bar{p} B}\right)\right)$

R

journal radius

$x, y, z$

circumferential, radial, and axial coordinates

$\theta, \bar{y}, \bar{z}$

dimensionless coordinates, $\theta=x / R, \bar{y}=y / a, \bar{z}=z /(L / 2)$

T

nondimensional time, $T=\omega_{p} t$

$\mathrm{t}$

time

$u, v, w$

radial, circumferential, and axial displacements

$W, \bar{W}$

steady-state load, $\left(\bar{W}=W c^{2} / n_{0} \omega R^{3} L\right)$

$\alpha$

piezo-viscosity coefficient

B

harmonic phase angle 


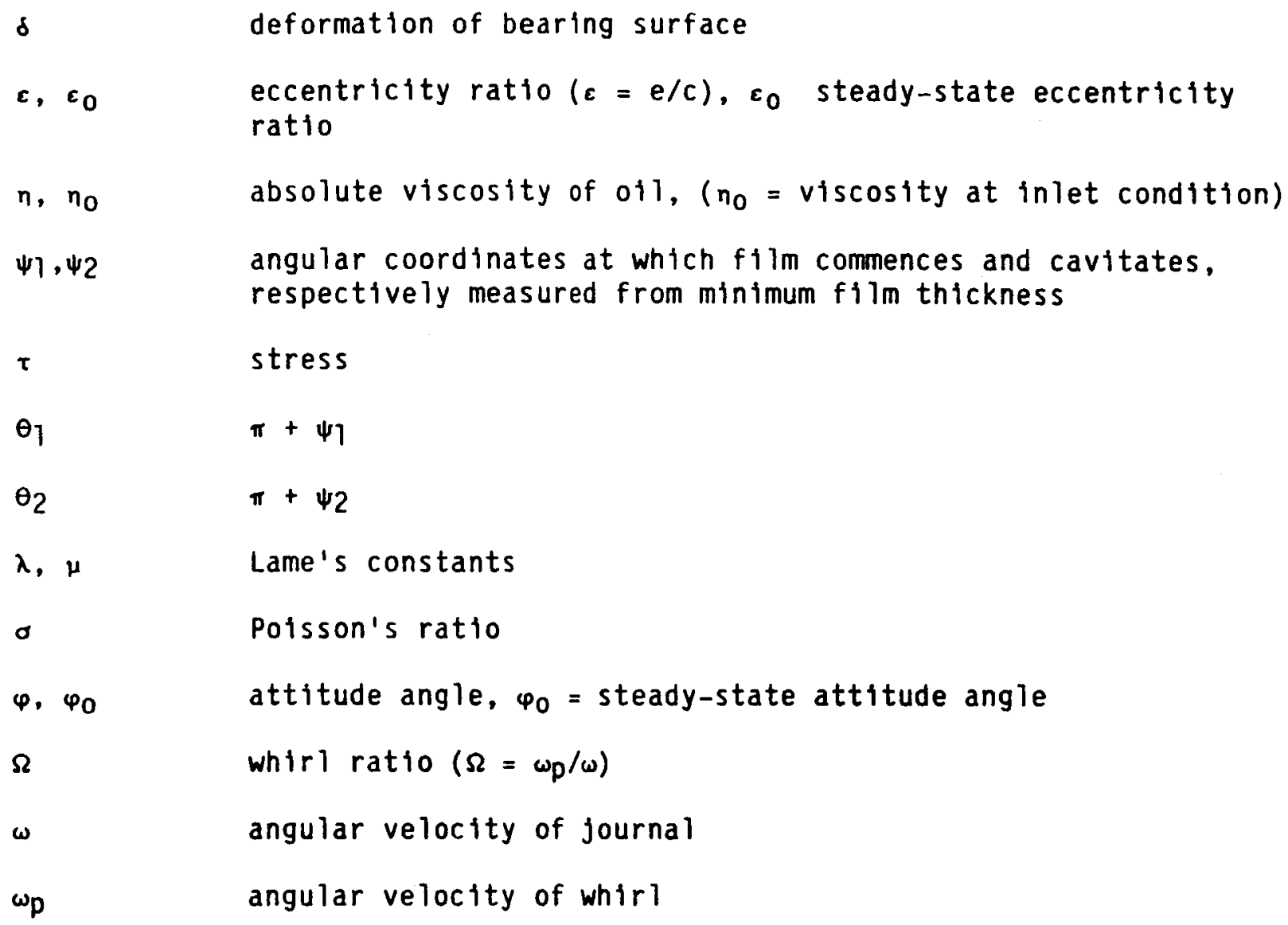

Theoretical research on flexible (soft shell) bearings with a rigid rotor was started with the work of Higginson (Ref. 1) using a simplified method (the distortion is proportional to the pressure). Since then many workers notably Hooke, Brighton, and 0'Donoghue (Refs. 2 to 4), Conway and Lee (Refs. 5 and 6 ), and 0 and Huebner (Ref. 7) solved the journal bearing problem considering the effect of elastic distortions of the bearing liner. In Refs. (2) and (3) the analysis dealt with the infinitely long bearing approximation. Brighton, Hooke, and 0 'Donoghue (Ref. 4) described the method of solution for finite bearings considering the effect of elastic distortions. This paper mentions some of the important experimental findings of Carl (Ref. 8). Bozaci et al. (Ref. 9) gave theoretical and experimental investigation of a finite journal bearing assuming that three-fourths of the bearing arc was a uniform thin ring and the remaining one-fourth was rigid. 
Conway and Lee used long and short bearing approximations, respectively in their papers (Ref. 5 and 6 ). Oh and Huebner (Ref. 7) used a finite-element method which was applied to finite journal bearings.

In recent years several workers have studied the effect of elastic distortion in dynamically loaded journal bearings (Refs. 10 to 13). From these studies the minimum film thickness as a function of crank angle of engine bearings can be determined.

The purpose of the present study is to identify the threshold of oil whirl for a rigid rotor in self-acting 011 journal bearings considering the elastic deformation of the bearing liner. The deformation of the liner is estimated by solving the displacement components in the elastic medium. In the stability study both the translatory and rotating components of journal vibration have been considered. Using a first-order perturbation method the time-dependent Reynolds equation is transformed in terms of steady-state and dynamic pressures. These pressures are solved by a finite-difference method using Reynolds boundary conditions. From the dynamic pressures the stiffness and damping coefficients are computed. These are then used in the equation of motion to find the mass parameter, which is a measure of stability. In the absence of experimental data, the theoretical mass parameters obtained by this analysis have been compared with the avallable results of rigid bearings.

\section{THEORY}

Using the normal assumptions in the theory of hydrodynamic lubrication the differential equation in the bearing clearance of an oil-lubricated bearing as shown in Fig. 1 is

$$
\frac{\partial}{\partial x}\left(h^{3} \frac{\partial p}{\partial x}\right)+\frac{\partial}{\partial z}\left(h^{3} \frac{\partial p}{\partial z}\right)=6 \eta_{0} \omega R\left(1-\frac{2}{\omega} \frac{\partial \varphi}{\partial t}\right) \frac{\partial h}{\partial x}+12 n_{0}\left(\frac{\partial h}{\partial t}\right)
$$


Eq. (1) when nondimensionalized with the following substitutions,

$$
\begin{gathered}
\theta=\frac{x}{R}, \bar{h}=\frac{h}{c}, \bar{z}=\frac{z}{\frac{L}{2}}, \bar{p}=\frac{p c^{2}}{\eta_{0} \omega R^{2}}, T=\omega_{p} t \text {, and } \Omega=\frac{\omega_{p}}{\omega} \text {, will read as: } \\
\frac{\partial}{\partial \theta}\left(\hbar^{3} \frac{\partial \bar{p}}{\partial \theta}\right)+\left(\frac{D}{L}\right)^{2} \frac{\partial}{\partial \bar{z}}\left(\hbar^{3} \frac{\partial \bar{p}}{\partial \bar{z}}\right)=6\left(1-2 \Omega \frac{\partial \phi}{\partial T}\right) \frac{\partial \bar{h}}{\partial \theta}+12 \Omega \frac{\partial \bar{h}}{\partial T}
\end{gathered}
$$

The steady-state film thickness $h_{0}$ in the case of a flexible bearing is given by

$$
\bar{h}_{0}=1+\varepsilon_{0} \cos \theta+\frac{\delta}{c}(\theta, \bar{z})
$$

where $\delta$ is the deformation of the bearing surface.

Before trying to find the solution of Eq. (1) satisfying the appropriate boundary conditions the elastic deformation $\delta$ is obtained in the following way:

The method is similar to that of Brighton et a1. (Ref. 4). In the present calculation the three displacement components $u, v$, and $w$ are solved simultaneously satisfying the boundary conditions. Brighton et al. (Ref. 4), however, used an approximate method to evaluate the displacements. The method is briefly given below.

The pressure distribution in the bearing clearance of the rigid bearing is first calculated by solving the two-dimensional steady-state Reynolds equation. The film pressure is then expressed in a double Fourier series of the form:

$$
p=\sum_{m}^{\prime} \sum_{n}^{\prime} p_{m, n} \cos \frac{2 m \pi z}{L} \cos \left(n \theta+B_{m, n}\right)
$$

where $\sum$ indicates the first term of the series is halved, and $p_{m, n}$ and $\beta_{m, n}$ are given by 


$$
\begin{aligned}
& p_{m, n}=\frac{2}{\pi L}\left[\left\{\int_{0}^{2 \pi} \int_{0}^{1 . / 2} p \cos \right.\right.\left.\frac{2 m \pi z}{L} \cos n \theta d z d \theta\right\}^{2} \\
&\left.+\left\{\int_{0}^{2 \pi} \int_{0}^{L / 2} p \cos \frac{2 m \pi z}{L} \sin n \theta d z d \theta\right\}\right]^{1 / 2} \\
& \beta_{m, n}=\tan ^{-1}\left[\frac{\left.-\int_{0}^{2 \pi} \int_{0}^{L / 2} p \cos \frac{2 m \pi z}{L} \sin n \theta d z d \theta\right]}{\left.\int_{0}^{L / 2} \int_{0}^{L} p \cos \frac{2 m \pi z}{L} \cos n \theta d z d \theta\right]}\right.
\end{aligned}
$$

The first term of the right-hand side of Eq. (4) is $1 / 2 \mathrm{P}_{0,0}$. When the condition at the end of bearing $(p=0$ at $z=L / 2)$ is used, one can obtain $p_{0,0}$. Although this term does not contribute any deformation at $z=L / 2$, its effect for other values of $z$ is already included in the total deformation. The boundary conditions of the inner radius are

$$
\left.\begin{array}{rl}
\tau_{r r} & =-p \\
\tau_{r \theta} & =0 \\
\tau_{r z} & =0
\end{array}\right\}
$$

The outer surface is rigidly enclosed by the housing preventing any displacement of the outer surface. The ends of the bearing are prevented from expanding axtally, but are free to move circumferentially or radially.

The displacement components in $r, \theta$, and $z$ directions were found from the pressure distribution which had been expressed in a Fourier series.

These displacements were substituted in the stress-strain relationships using Lame's constants. The six components of stresses were then used in the equations of equilibrium to obtain the following three displacement equations. 


$$
\begin{aligned}
& C \frac{d^{2} u}{d \bar{y}^{2}}+\frac{c}{\bar{y}} \frac{d u}{d \bar{y}}-\left(C+n^{2}\right) \frac{u}{\bar{y}^{2}}+(C-1) \frac{n^{2}}{\bar{y}} \frac{d v}{d \bar{y}} \\
& -(c+1) \frac{n^{2}}{\bar{y}^{2}} v-\frac{k^{2}}{a^{2}} u+(c-1) \frac{k^{2}}{a^{2}} \frac{d w}{d \bar{y}}=0 \\
& \frac{d^{2} v}{d \bar{y}^{2}}+\frac{1}{\bar{y}} \frac{d v}{d \bar{y}}-\left(1+C n^{2}\right) \frac{v}{\bar{y}^{2}}-\frac{k^{2}}{a^{2}} v \\
& -(C-1) \frac{1}{\bar{y}} \frac{d u}{d \bar{y}}-(C+1) \frac{u}{\bar{y}^{2}}-\frac{k^{2}}{a^{2}}(C-1) \frac{w}{\bar{y}}=0 \\
& \left.\frac{d^{2} w}{d \bar{y}^{2}}+\frac{1}{\bar{y}} \frac{d w}{d \bar{y}}-n^{2} \frac{w}{\bar{y}^{2}}-c \frac{k^{2}}{a^{2}} w-(C-1) \frac{d u}{d \bar{y}}-(C-1) \frac{u}{\bar{y}}-n^{2}(C-1) \frac{v}{\bar{y}}=0\right)
\end{aligned}
$$

where

$$
C=2+\frac{\lambda}{\mu}, k=\frac{2 m \pi a}{L}
$$

The boundary conditions are:

$$
\text { At } \begin{aligned}
\bar{y}=1, c \frac{d u}{d \bar{y}}=-\frac{1}{\mu}-(c-2)\left(\frac{n^{2} v}{\bar{y}}+\frac{u}{\bar{y}}+\frac{\left.k^{2} w\right)}{a^{2}}\right. \\
\frac{d v}{d \bar{y}}=\frac{u}{\bar{y}}+\frac{v}{\bar{y}} \\
\frac{d w}{d \bar{y}}=u
\end{aligned}
$$

and

$$
\text { at } \bar{y}=\frac{b}{a}, u=v=w=0
$$

Equation (7) was solved using finite-difference methods for unit pressure, $\mu$ and $R$, and the values of $d_{m, n}$ were obtained and expressed as

$$
d_{m, n}=\frac{\mu U}{R p}
$$

The deformation $\delta$ of the bearing surface will be

$$
\delta=\sum^{\prime} \sum^{\prime} p_{m, n} d_{m, n} \cos \frac{2 m \pi z}{L}\left(\cos n \theta+\beta_{m, n}\right)
$$


Knowing the distortion coefficients $d_{m, n}$ and using the expressicis for $P_{m, n}$ and $B_{m, n}$ from Eq. (5) \& at any point $(\theta, \bar{z})$ was computed. Using $\bar{p}=p c^{2} / n_{0} \omega R^{2}$ and $\bar{z}=z /(L / 2)$, the radial deformation in the inner bearing surface is

$$
\frac{\delta}{c}=2(1+\sigma) F \quad \sum^{\prime} \sum^{\prime} \bar{p}_{m, n} d_{m, n} \cos m \pi \bar{z} \cos \left(n \theta+\beta_{m, n}\right) \bar{p}(\theta, \bar{z})
$$

Here $\mu$ is replaced by $E / 2(1+\sigma)$ and $F=\eta_{0} \omega R^{3} / E c^{3}$.

Let us now solve Eq. (2). The boundary conditions are:

and

$$
\begin{aligned}
& \bar{p}(\theta, \pm 1)=0 \\
& \frac{\partial \bar{p}}{\partial \bar{z}}(\theta, 0)=0
\end{aligned}
$$

$$
\left.\begin{array}{l}
\bar{p}(\theta, \bar{z})=0 \\
\frac{\partial \bar{p}}{\partial \bar{z}}=\frac{\partial \bar{p}}{\partial \theta}=0
\end{array}\right\} \theta_{2} \leq \theta \leq \theta_{1}
$$

where $\theta_{2}$ is the angular coordinate where film cavitates.

Assuming that the journal whirls about its mean steady-state-position given by $\varepsilon_{0}$ and $\varphi_{0}$, for the first-order perturbation, the pressure and film thickness can be expressed as

and

$$
\bar{p}=\bar{p}_{0}+\bar{p}_{1} \varepsilon_{1} e^{i T}+\bar{p}_{2} \varepsilon_{0} \phi_{1} e^{i T}
$$

$$
\left.\hbar=\hbar_{0}+\varepsilon_{1} e^{i T} \cos \theta+\varepsilon_{0} \phi_{1} e^{i T} \sin \theta \quad\right\}
$$

where

$$
\begin{aligned}
& \varepsilon=\varepsilon_{0}+\varepsilon_{1} e^{i T} \\
& \varphi=\varphi_{0}+\varphi_{1} e^{i T}
\end{aligned}
$$

Substituting Eq. (13) into Eq. (2) and collecting the zeroth and the firstorder terms for $\varepsilon_{1}$ and $\varepsilon_{0} \varphi_{1}$, the following set of equations result 


$$
\begin{aligned}
& \frac{\partial}{\partial \theta}\left(\hbar_{0}^{3} \frac{\partial \bar{p}_{0}}{\partial \theta}\right)+\left(\frac{D}{L}\right)^{2} \frac{\partial}{\partial \bar{z}}\left(\hbar_{0}^{3} \frac{\partial \bar{p}_{0}}{\partial \bar{z}}\right)=6 \frac{\partial \hbar_{0}}{\partial \theta} \\
\frac{\partial}{\partial \theta}\left(\hbar_{0} \frac{\partial \bar{p}_{1}}{\partial \theta}\right)+\left(\frac{D}{L}\right)^{2} & \frac{\partial}{\partial \bar{z}}\left(\hbar_{0} \frac{\partial \bar{p}_{l}}{\partial \bar{z}}\right)+3 \frac{\partial}{\partial \theta}\left(\hbar_{0}^{2} \frac{\partial \bar{p}_{0}}{\partial \theta} \cos \theta\right) \\
& +3\left(\frac{D}{L}\right)^{2} \frac{\partial}{\partial \bar{z}}\left(\hbar_{0}{ }^{2} \frac{\partial \bar{p}_{0}}{\partial \bar{z}} \cos \theta\right)=-6 \sin \theta+i(12 \Omega \cos \theta)
\end{aligned}
$$

and

$$
\begin{aligned}
\frac{\partial}{\partial \theta}\left(\hbar_{0}{ }^{3} \frac{\partial \bar{p}_{2}}{\partial \theta}\right) & +\left(\frac{D}{L}\right)^{2} \frac{\partial}{\partial \bar{z}}\left(\hbar_{0}^{3} \frac{\partial \bar{p}_{2}}{\partial \bar{z}}\right)+3 \frac{\partial}{\partial \theta}\left(\hbar_{0}^{2} \frac{\partial \bar{p}_{0}}{\partial \theta} \sin \theta\right) \\
& +3\left(\frac{D}{L}\right)^{2} \frac{\partial}{\partial z}\left(\hbar_{0}^{2} \frac{\partial \bar{p}_{0}}{\partial \bar{z}} \sin \theta\right)=6 \cos \theta+i(24 \Omega \sin \theta)-i\left(\frac{12 \Omega}{c_{0} c} \frac{\partial \delta}{\partial \theta}\right)
\end{aligned}
$$

Steady-state Solution

The bearing pressure was first obtained from Eq. (15) assuming a constant film shape (1.e., $\left.\bar{h}_{0}=1+\varepsilon_{0} \cos \theta\right)$ and using a finite-difference method (Gauss-Seide1) with successive overrelaxation scheme. The distribution was expressed as a double fourter series as given by Eq. (4). The deformation $8 / \mathrm{C}$ (Eq. (11)) was then calculated for a given $F$ using distortion coefficients from Eq. (9). The film thickness equation was then modified using Eq. (3). The process was repeated until a compatible film shape and pressure distribution was determined. The steady-state load and attitude angle are 


$$
\begin{gathered}
\left.\bar{W}=\left[\left\{\int_{\theta_{1}}^{\theta_{2}} \int_{0}^{1} \bar{p}_{0} \cos \theta d \theta d \bar{z}\right\}^{2}+\iint_{\theta_{1}}^{\theta_{2}^{2}} \int_{0}^{1} \bar{p}_{0} \sin \theta d \theta d \bar{z}\right\}^{2}\right]^{\frac{1}{2}} \\
\phi_{0}=\tan ^{-1} \frac{\left(-\int_{\theta_{1}}^{\theta^{2}} \int_{0}^{1} \bar{p}_{0} \sin \theta d \theta d \bar{z}\right)}{\left(\int_{\theta_{1}}^{\theta_{2}} \int_{0}^{1} \bar{p}_{0} \cos \theta d \theta d \bar{z}\right)}
\end{gathered}
$$

Solution Under Dynamic Condition

Having obtained the steady-state pressure distribution of a journal bearing having various $L / D(0.5,1.0$, and 2.0$), c_{0}(0.6,0.8$, and 0.85$)$, and $F(0,0.05,0.1,0.2$, and 0.4$)$ for a constant value of $H / R=0.3$ and $\sigma=0.4$, the pressure distribution under dynamic condition was obtained. Liner thickness to radius ratio of 0.3 and Poisson's ratio of 0.4 were taken in the present calculation for the purpose of comparison of steady-state results of Brighton et al. (Ref. 4). The method, however, can handle any reasonable value of $H / R$ and $\sigma$ up to 0.49 . For this purpose Eqs. (16) and (17) are solved satisfying the appropriate boundary conditions by a finite-difference method using a successive overrelaxation scheme.

\section{Stiffness and Damping Coefficients}

Nondimensional stiffness and damping coefficlents can be shown to be (Ref. 15) 


$$
\begin{aligned}
& R_{r r}=-\operatorname{Re}\left[\int_{\theta_{1}}^{\theta_{2}} \int_{0}^{1} \bar{p}_{1} \cos \theta d \theta d \bar{z}\right] \\
& \bar{R}_{\varphi \varphi}=-\operatorname{Re}\left[\int_{\theta_{1}}^{\theta_{2}} \int_{0}^{1} \bar{p}_{2} \sin \theta d \theta d \bar{z}\right] \\
& R_{r \varphi}=-\operatorname{Re}\left[\int_{\theta_{1}}^{\theta_{2}} \int_{0}^{1} \bar{p}_{2} \cos \theta d \theta d \bar{z}\right. \\
& R_{\varphi r}=-\operatorname{Re}\left[\int_{\theta_{1}}^{\theta_{2}} \int_{0}^{1} \bar{p}_{1} \sin \theta d \theta d \bar{z}\right. \\
& \bar{D}_{r r}=\frac{-I m\left[\int_{\theta_{1}}^{\theta_{2}} \int_{0}^{1} \bar{p}_{1} \cos \theta d \theta d \bar{z}\right]}{\Omega}
\end{aligned}
$$

$$
\bar{D}_{\varphi \varphi}=\frac{-\operatorname{Im}\left[\int_{\theta_{1}}^{\theta_{2}} \int_{0}^{1} \bar{p}_{2} \sin \theta d \theta d \bar{z}\right]}{\Omega}
$$$$
\bar{D}_{r \varphi}=\frac{-\operatorname{Im}\left[\int_{\theta_{1}}^{\theta_{2}} \int_{0}^{1} \bar{p}_{2} \cos \theta d \theta d \bar{z}\right]}{\Omega}
$$$$
\vec{D}_{\varphi r}=\frac{-I m\left[\int_{\theta_{1}}^{\theta_{2}} \int_{0}^{1} \bar{p}_{1} \sin \theta d \theta d \bar{z}\right]}{\Omega}
$$ 


\section{Stability Characteristics}

Referring to Fig. 1, the equations of motion of the rigid journal, along the line of centers and its perpendicular direction can be written as

and

$$
M c\left[\frac{d^{2} \varepsilon}{d t^{2}}-c\left(\frac{d \phi}{d t}\right)^{2}\right]=F_{r}+W \cos \varphi
$$

$$
M c\left[=\frac{d^{2} \varphi}{d t^{2}}+2\left(\frac{d \phi}{d t}\right)\left(\frac{d \varepsilon}{d t}\right)\right]=F_{\varphi}-W \sin \varphi
$$

$F_{r}$ and $F_{\varphi}$ are the resultant film forces in the $r$ and $\varphi$ directions.

For steady-state

$$
\left.\begin{array}{l}
F_{r_{0}}+W \cos \varphi_{0}=0 \\
F_{\varphi 0}-W \sin \varphi_{0}=0
\end{array}\right\}
$$

Substituting Eqs. (14) and (23) into Eqs. (21) and (22) and nondimensionatizing, after neglecting second-order terms

$$
\begin{array}{r}
\left(-\bar{M} \Omega^{2} \bar{W}+1 \Omega \bar{D}_{r r}+\bar{K}_{r r}\right) \varepsilon_{1}+\left(1 \varepsilon_{0} \Omega \bar{D}_{r \varphi}+\varepsilon_{0} \bar{K}_{r_{\varphi}}+\bar{W} \sin \varphi_{0}\right) \varphi_{1}=0 \\
\left(i \Omega \bar{D}{ }_{\varphi r}+\bar{K}_{\varphi r}\right) \varepsilon_{1}+\left(-\bar{M}_{\Omega}^{2} \varepsilon_{0} \bar{W}+1 \Omega \varepsilon_{0} \bar{D}_{\varphi \varphi}+\varepsilon_{0} \bar{K}_{\varphi \varphi}+\bar{W} \cos \varphi_{0}\right) \varphi_{1}=0
\end{array}
$$

For a nontrivial solution the determinant of Eqs. (24) and (25) must vanish, and thus

$$
\begin{aligned}
\left(-\bar{M} \Omega^{2} \bar{W}+\bar{K}_{r r}+i \Omega \bar{D}_{r r}\right)\left(-\bar{M} \Omega^{2} \varepsilon_{0} \bar{W}+\varepsilon_{0} \bar{K}_{\varphi \varphi}+\bar{W} \cos \varphi_{0}+i \Omega \varepsilon_{0} \bar{D}_{\varphi \varphi}\right) \\
-\left(\varepsilon_{0} \bar{K}_{r \varphi}+\bar{W} \sin \varphi_{0}+1 \Omega \varepsilon_{0} \bar{D}_{r \varphi}\right)\left(\bar{K}_{\varphi r}+i \Omega \bar{D} \varphi r r\right)=0
\end{aligned}
$$

Equating imaginary and real terms of Eq. (26) to zero, we get the following two equations 


$$
\begin{aligned}
\bar{M} \bar{W}= & \frac{1}{\Omega^{2}\left(D_{\varphi \varphi}+\delta_{r r}\right)}\left[\left(\bar{K}_{r r} \bar{D}_{\varphi \varphi}+\bar{D}_{r r} \bar{K}_{\varphi \varphi}\right)-\left(\bar{D}_{r \varphi} \bar{K}_{\varphi r}\right.\right. \\
& \left.\left.+\bar{D}_{\varphi r} \bar{K}_{r \varphi}\right)-\frac{1}{\varepsilon_{0}}\left(\bar{D}_{\varphi r} \bar{W} \sin \varphi_{0}-\bar{D}_{r r} \bar{W} \cos \varphi_{0}\right)\right]
\end{aligned}
$$

$(M \bar{W})^{2} \Omega^{4}-\Omega^{2}\left[\bar{M}\left(R_{\varphi \varphi}+R_{r r}+\frac{\bar{W} \cos \varphi_{0}}{\varepsilon_{0}}\right)+\left(\bar{D}_{r r} \bar{D}_{\varphi \varphi}-\bar{D}_{r \varphi} \bar{D}_{\varphi r}\right)\right]$

$$
+\left(\bar{K}_{r r} \bar{K}_{\varphi \varphi}-\bar{K}_{\varphi r} \bar{K}_{r \varphi}\right)+\frac{1}{\varepsilon_{0}}\left(\bar{K}_{r r} \bar{W} \cos \varphi_{0}-\bar{K}_{\varphi r} \bar{W} \sin \varphi_{0}\right)=0
$$

From the above two equations $\bar{M}$ and $\Omega$ can be calculated. $\bar{M}$ is the

critical mass parameter above which the bearing is unstable.

Study Under Variable Viscosity 011

In the foregoing sections a scheme was devised for the analysis of the constant viscosity 011 . We now consider the case of vartable viscosity. The viscosity of most oils increases with pressure and the following relationship is assumed

$$
\eta=n_{0} e^{\alpha p}
$$

where $n_{0}$ viscosity of the ofl at the inlet condition

a piezo-viscosity coefficient.

The Reynolds equation under steady-state conditions for the variable viscosity case is

$$
\begin{gathered}
\frac{\partial}{\partial \theta}\left(\hbar_{0} 3 \frac{\partial \bar{q}_{0}}{\partial \theta}\right)+\left(\frac{D}{L}\right)^{2} \frac{\partial}{\partial \bar{z}}\left(\hbar_{0}^{3} \frac{\partial \bar{q}_{0}}{\partial \bar{z}}\right)=6 \frac{\partial \hbar_{0}}{\partial \theta} \\
\bar{q}_{0}=\frac{1}{B}\left(1-e^{-\bar{p}_{0} B}\right) \\
B=\frac{\eta_{0} \alpha \omega R^{2}}{c^{2}}
\end{gathered}
$$

and

The constant B can also be expressed as

$$
B=F \cdot G\left(\frac{c}{R}\right)
$$


where $G=\alpha E$.

It may be seen Eq. (30) is of the same form as that of Eq. (15). In this case $q$ may be referred to as the modified pressure. We can solve $q_{0}$ following a similar approach. After knowing $q_{0}$ the pressure distribution $p_{0}$ can be found using Eq. (31) for a given value of B. The elastic deformation $\delta$ is then obtained from Eq. (11). The process was repeated until the film shape and pressure were converged simultaneousiy. The stability study was then made using the method given in the previous section.

\section{RESULTS AND DISCUSSION}

The circumferential pressure distribution obtained from the present method of solution has been plotted in Fig. 2 for various values of $F$ for a particular bearing. It may be seen that the peak pressure decreases with increase in the elasticity parameter (i.e., for softer shells). In Table I the comparison of maximum centerline pressures in the circumferential direction of the present solution for a finite bearing with $L / D=1.0$, $\varepsilon_{0}=0.85$, and for values of $F$ varying from 0 to 0.4 with those of Ref. (4) are shown. Table II compares the mass parameter of the present solution with that of Allaire (Ref. 16) for a rigid bearing. Both tables indicate a fair agreement. The film thickness at the centerline in the circumferential direction is plotted in Fig. 3 . When $F=0.4$, the film profile at the high-pressure zone shows a similarity to that of an elastohydrodynamic point contact condition. Fig. 4 shows the steady-state load capacity variation with elasticity parameter for three eccentricity ratios (i.e., $\left.\varepsilon_{0}=0.6,0.8,0.85\right)$. Although there is little variation of load with $F$ at low eccentricity ratios, the load drops very sharply with $F$ at $\varepsilon_{0}=0.85$. This load goes below the one that is obtained at $\varepsilon_{0}=0.8$ when $F$ approaches a high value. The increase in $F$ increases the minimum film thickness. This in effect reduces the true eccentricity 
ratio, therefore pressures and load capacity drop. It may we mentioned that a similar observation has been made by Conway and Lee (Ref. 6) while analyzing a flexible bearing using the short bearing approximation. Because of the difficulty in convergency, it was not possible to study the effect of load at values of $\varepsilon_{0}>0.85$. As there is no effect of elastic parameter on the bearing performance for $\varepsilon_{0} \leq 0.6$, the results are presented for $\varepsilon_{0} \geq 0.6$.

In Figs. 5 and 6 the stiffness and damping coefficients for the isoviscous case have been plotted for $\varepsilon_{0}=0.6$ and 0.8 . It is evident, there is little variation of these coefficients for $\varepsilon_{0}=0.6$. However, some stiffness and damping coefficlents $\left(\bar{K}_{r r}, \bar{K}_{r_{\varphi}}, \bar{D}_{r r}\right)$ at $\varepsilon_{0}=0.8$ vary significantly with $F$. An increase in distortion of the liner causes the direct-coupled radial stiffness coefficient to decrease while the direct damping coefficient increases. The reverse effect was noted for the cross-coupled $r-\varphi$ stiffness and damping coefficients. Further, all other stiffness and damping coefficients were relatively unaffected by the flexibllity of the bearing liner.

Eccentricity ratio plays an important part in the margin of stability. This can be seen from fig. 7. The stability threshold falls rapidiy with $F$ at higher eccentricity ratios. When one studies the stability behavior of a rigid bearing, it is revealed that the stablitty is not a problem at high eccentricity ratios. In other words, a rigid bearing is highly stable at high eccentricity ratios. This can also be verified from Table II. However, for a flexible bearing liner the converse is true. The whirl ratio (Fig. 8) also increases very sharply with $F$ for $\varepsilon_{0}=0.85$ and it goes well above 0.5 . This is a perfect example of the latitude that can be taken with the meaning of "half-frequency whirl" since the whiri ratio for instability occurs at values generally close to, but different from 0.5 . 
The effect of L/D ratio on stablilty is shown in Fig. 9 for a particular value of $F=0.2$. It is seen that the bearing is highly stable when $L / D$ is small but drops drastically as $L / D$ increases from 0.5 to 1 . The stability margin does not decrease much when L/D increases from 1 to 2 . A similar trend is also seen for other values of $F$.

In figs. 10 and 11 the variation of stability and whirl ratio on the pressure-dependent viscosity is shown. The stability is seen to improve with increasing $B$ for all values of $\varepsilon_{0}$ while the whirl ratio generally decreases with increasing $B$.

\section{CONCLUSIONS}

Numerical methods are used to determine the effects of elastic distortions in the bearing liner on bearing performance and stability for a finite journal bearing. A linearization method using a first-order perturbation theory was used for the stability analysis. The following conclusions were evident:

1. The region of stability decreases as the bearing liner is made more flexible for high eccentricity ratios (i.e., $\varepsilon_{0}>0.8$ ). For $\varepsilon_{0} \leq 0.8$, the flexibility of the bearing liner had little or no effect on stability.

2. As $L / D$ is increased, distortion effects are more prominent. This leads to a decrease in stabllity.

3. An increase in distortion of the liner causes the direct-coupled radial stiffness coefficient to decrease while the direct damping coefficient increases. The reverse effect was noted for the cross-coupled $r-\varphi$ stiffness and damping coefficients. Further, all other stiffness and damping coefficients were relatively unaffected by the flexiblitity of the bearing liner. 
4. The hydrodynamic pressure and hence the load capacity is reuuced as the bearing liner becomes more flexible, especially at eccentricities greater than 0.8 .

5. As the bearing liner becomes softer, the whirl ratio, $\Omega$, remains relatively constant (1.e., $0.46 \leq \Omega \leq 0.53$ ) for $\varepsilon_{0}=0.6$ and 0.8 . For $\varepsilon_{0}=0.85$ the whirl ratio changed drastically (1.e., $\left.0.30 \leq \Omega \leq 0.58\right)$ with an increase in the elasticity parameter.

6. The stability increases for increasing viscosity of the oil.

\section{REFERENCES}

1. Higginson, G.R., 1965-66, "The Theoretical Effects of Elastic Deformation of the Bearling Liner on Journal Bearing Performance," Elastohydrodynamic Lubrication, Proc. Inst. Mech. Eng., Vol. 180, Part 38, pp. 31-37.

2. Hooke, C.J., Brighton, D.K., and O'Donoghue, J.P., 1966-67, "The Effect on Elastic Distortions on the Performance of Thin Shell Bearings, " Journal Bearings for Reciprocating and Turbo Machinery, Proc. Inst. Mech. Eng., Vo1. 181, Part 38, pp. 63-69.

3. O'Donoghue, J., Brighton, D.K., and Hooke, C.J.K., 1967, "The Effect of Elastic Distortion on Journal Bearing Performance," Journal of Lubrication Technology, Vo1. 89, No. 4, pp. 409-417.

4. Brighton, D.K., Hooke, C.J., and O'Donoghue, J.P., 1967-68, "A Theoretical and Experimental Investigation on the Effect of Elastic Distortions on the Performance of Journal Bearings," Trtbology Convention 1968, Proc. Inst. Mech. Eng., Vol. 182, Part 3N, pp. 192-200.

5. Conway, H.D., and Lee, H.C., 1975, "The Analys is of the Lubrication of a Flexible Journal Bearing," Journal of Lubrication Technology, Vol. 97, No. 4, 1975, pp. 599-604.

6. Conway, H.D. and Lee, H.C., 1977, "The Lubrication of Short Flexible Bearings," Journal of Lubrication Technology, Vol. 99, No. 3, pp. 376-378. 
7. Oh, K.P. and Huebner, K.H., 1973, "Solution of the Elastohydrodynamic Finite Journal Bearing Problem," Journal of Lubrication Technology, Vol. 95, No. 3, pp. 342-352.

8. Carl, T.E., 1963-64, "An Experimental Investigation of a Cylindrical Journal Bearing Under Constant and Sinusoidal Loading," Lubrication and Wear, Second Convention, Proc. Inst. Mech. Eng., Vol. 178, Part 3N, pp. 100-119.

9. Bozaci, A., Dudley, B.R., Middleton, V., and Allen, D.G., 1978, "Steady Load Performance of a Journal Bearing With an Elastic Housing," Elastohydrodynamics and Related Topics, D. Dowson, et al., eds., Mechanical Engineering Publications, London, pp. 320-328.

10. Frene, J., Desalliy, R., and Fantino, B., 1978, "Hydrodynamics of an Elastic Connecting-Rod Bearing: Comparison of Theoretical and Experimental Results," Elastohydrodynamics and Related Topics, D. Dowson, et al., eds., Mechanical Engineering Publications, London, pp. 329-336.

11. Van der Tempe1, L., Moes, H., and Bosma, R., 1985, "Numerical Simulation of Dynamically Loaded Flexible Short Journal Bearings, " Journal of Irtbology, Vo1. 107, No. 3, pp. 396-401.

12. Fantino, B. and Frene, J., 1985, "Comparison of Dynamic Behavior of Elastic Connecting-Rod Bearing in Both Petrol and Diesel Engines, Journal of Tribology, Vol. 107, No. 1, pp. 87-91.

13. On, K.P. and Goenka, P.K., 1985, "The Elastohydrodynamic Solution of Journal Bearings Under Dynamic Loading," Journal of Tribology, Vol. 107, No. 3 , pp. 389-395.

14. Van der Tempel, L., Moes, H., and Bosma, R., 1985, "Starvation in Dynamically Loaded Flexible Short Journal Bearings, " Journal of Tribology, Vo1. 107, No. 4, pp. 516-521. 
15. Majumdar, B.C., 1983, "Stiffness and Damping of Externally Pressurized Gas Journal Bearings with Porous Inserts," Proc. Inst. Mech. Eng., Part C, Mechanical Engineering Science, Vol. 197, No. 1, pp. 25-29.

16. Allaire, P.E., 1979, "Design of Journal Bearings for High-Speed Rotating Machinery," Fundamentals of the Design of Fluid Film Bearings, S.M. Rohde, C.J. Muday, and P.E. Allaire, eds., ASME, New York, pp. 45-83.

TABLE I. - COMPARISON OF MAXIMUM STEADY-STATE PRESSURE OBTAINED BY THE PRESENT METHOD TO THAT OF BRIGHTON ET AL. (4) $\left[L / 0=1.0, \varepsilon_{0}=0.85\right.$, $H / R=0.3, \sigma=0.4]$

\begin{tabular}{|l|r|r|}
\hline$F$ & $\bar{P}_{\max }$ & $\bar{P}_{\max }{ }^{\mathrm{a}}$ \\
\hline 0 & 17.25 & 16.80 \\
0.05 & 13.50 & 14.10 \\
.10 & 11.50 & 11.40 \\
.20 & 9.00 & 8.70 \\
.40 & 6.25 & 6.30 \\
\hline
\end{tabular}

a Indicates the results by Brighton et al. (Ref. 4).
TABLE II. - COMPARISON OF THE PRESENT SOLUTION WITH THAT OF ALLAIRE (마) FOR RIGID CYLINDRICAL JOURNAL BEARING

$[L / D=1.0, F=0]$
\begin{tabular}{|c|c|c|}
\hline$\varepsilon_{0}$ & $\bar{M}$ & $\bar{M} a$ \\
\hline 0.1 & 6.950 & 6.8 \\
.3 & 7.512 & 6.8 \\
.8 & 15.45 & 16.0 \\
\hline
\end{tabular}

a Indicates the results by Allaire (Ref. 16). 

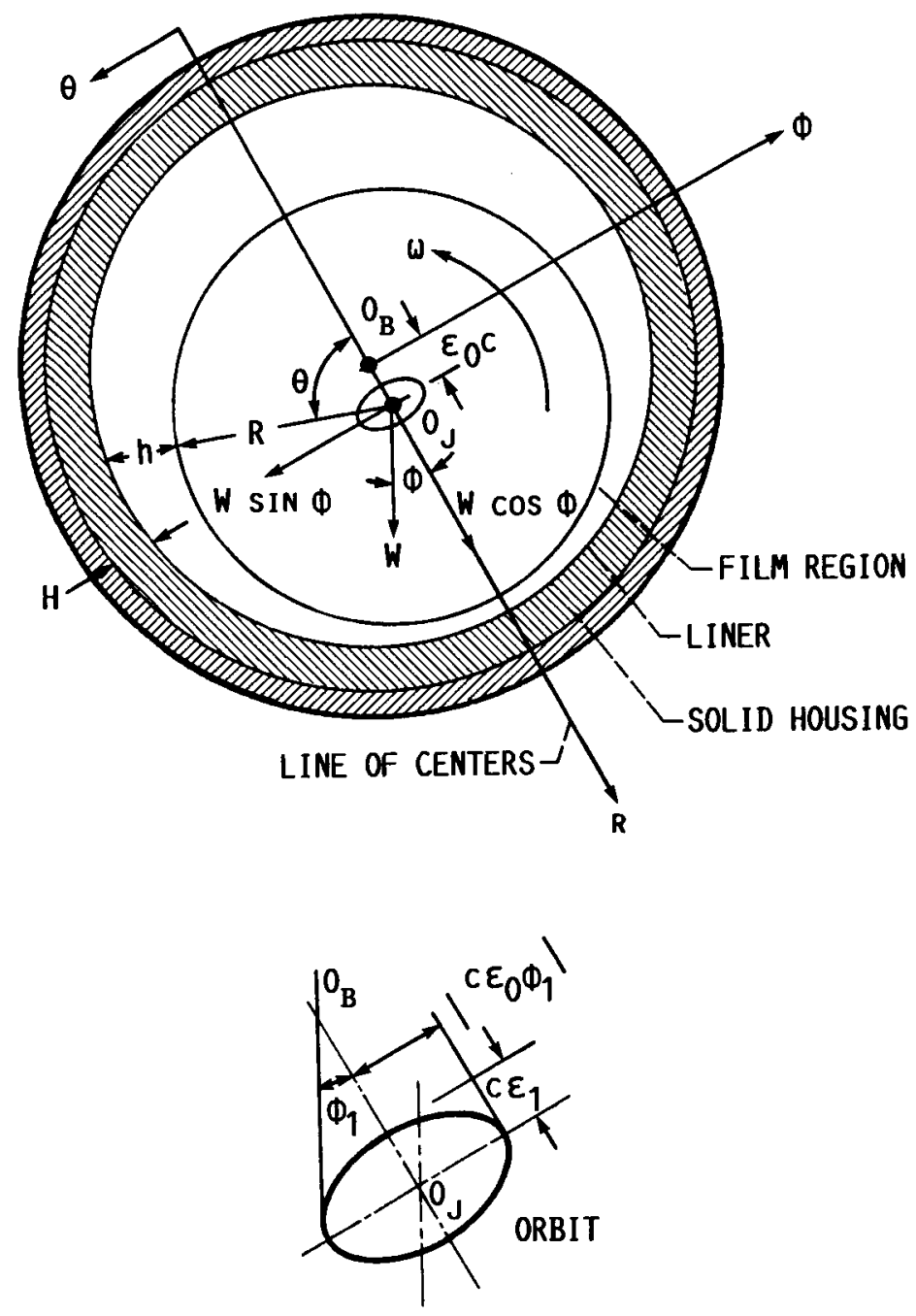

FIGURE 1. - SCHEMATIC DIAGRAM OF A JOURNAL BEARING. 


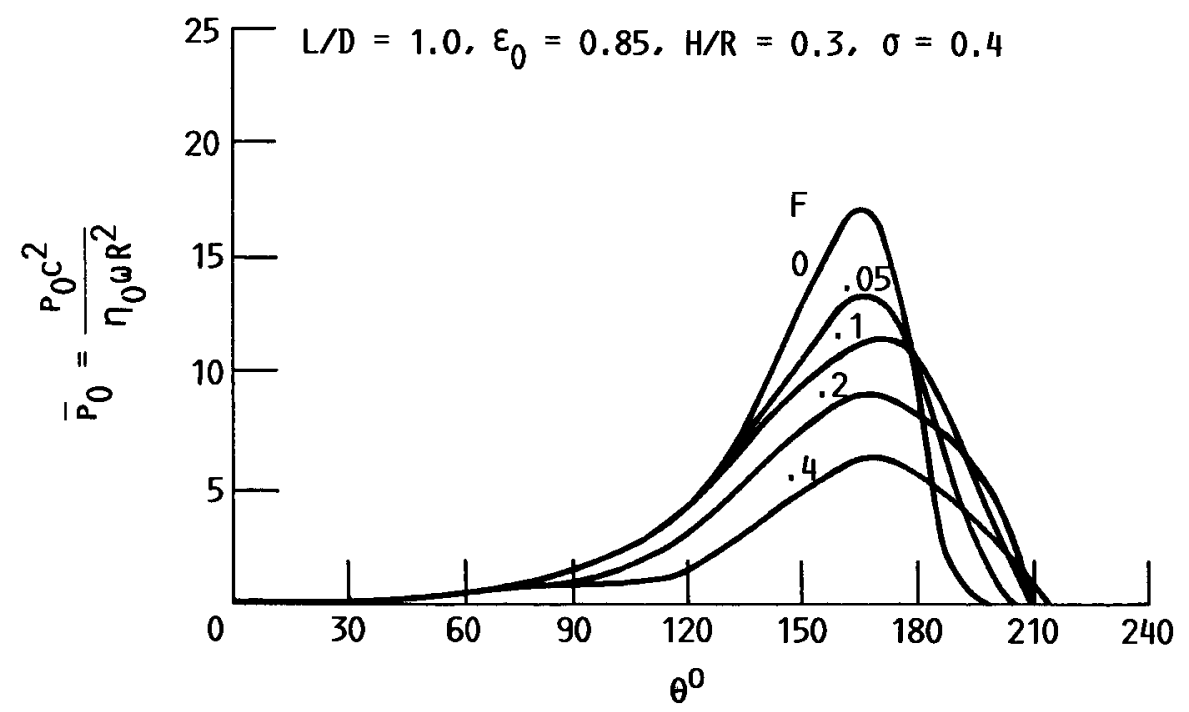

FIGURE 2. - CIRCUMFERENTIAL PRESSURES AT THE CENTERLINE (ISOVISCOUS).

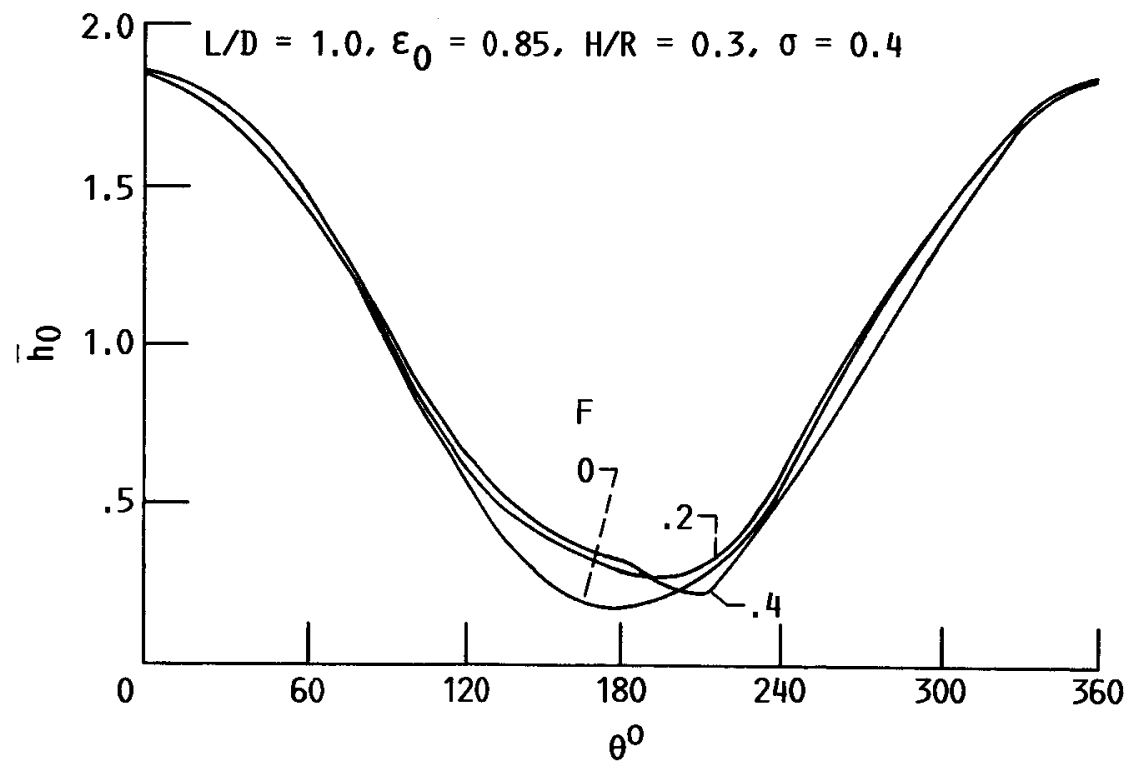

FIGURE 3. - FILM THICKNESS AT THE CENTERLINE (ISOVISCOUS). 


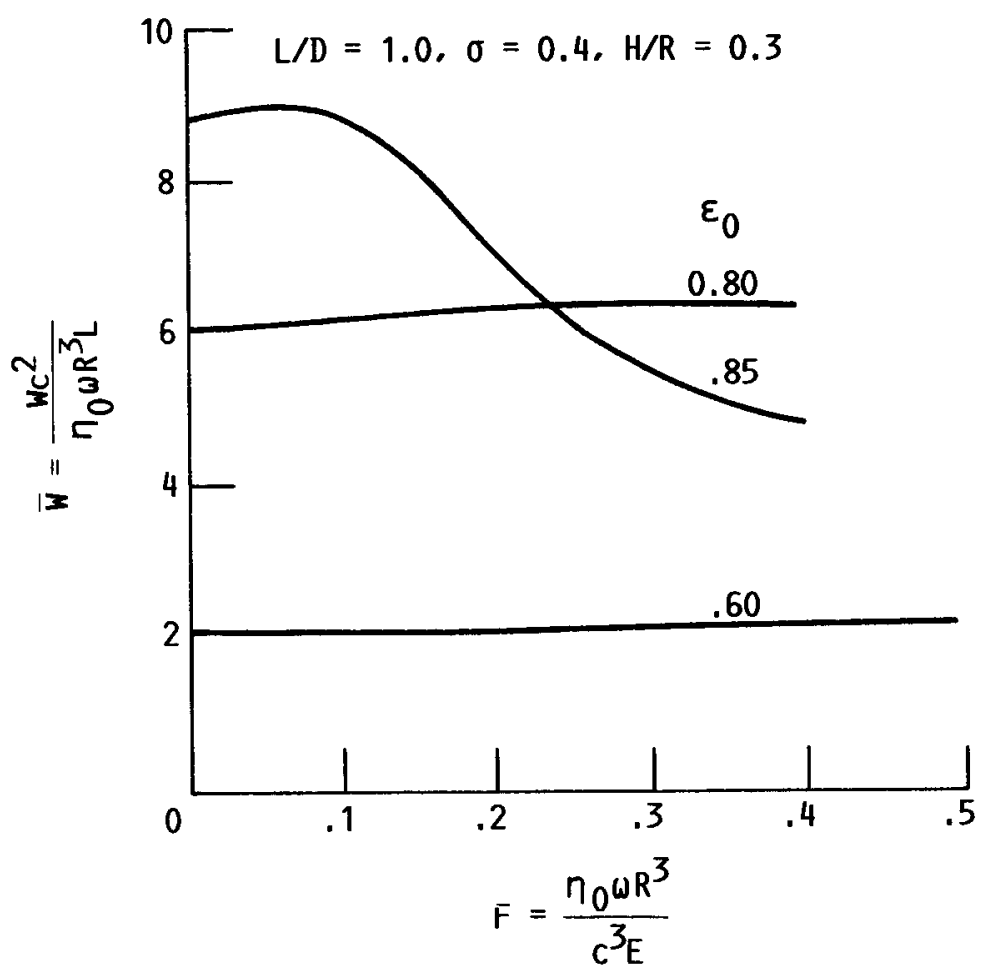

FIGURE 4. - STEADY-STATE LOAD (ISOVISCOUS). 


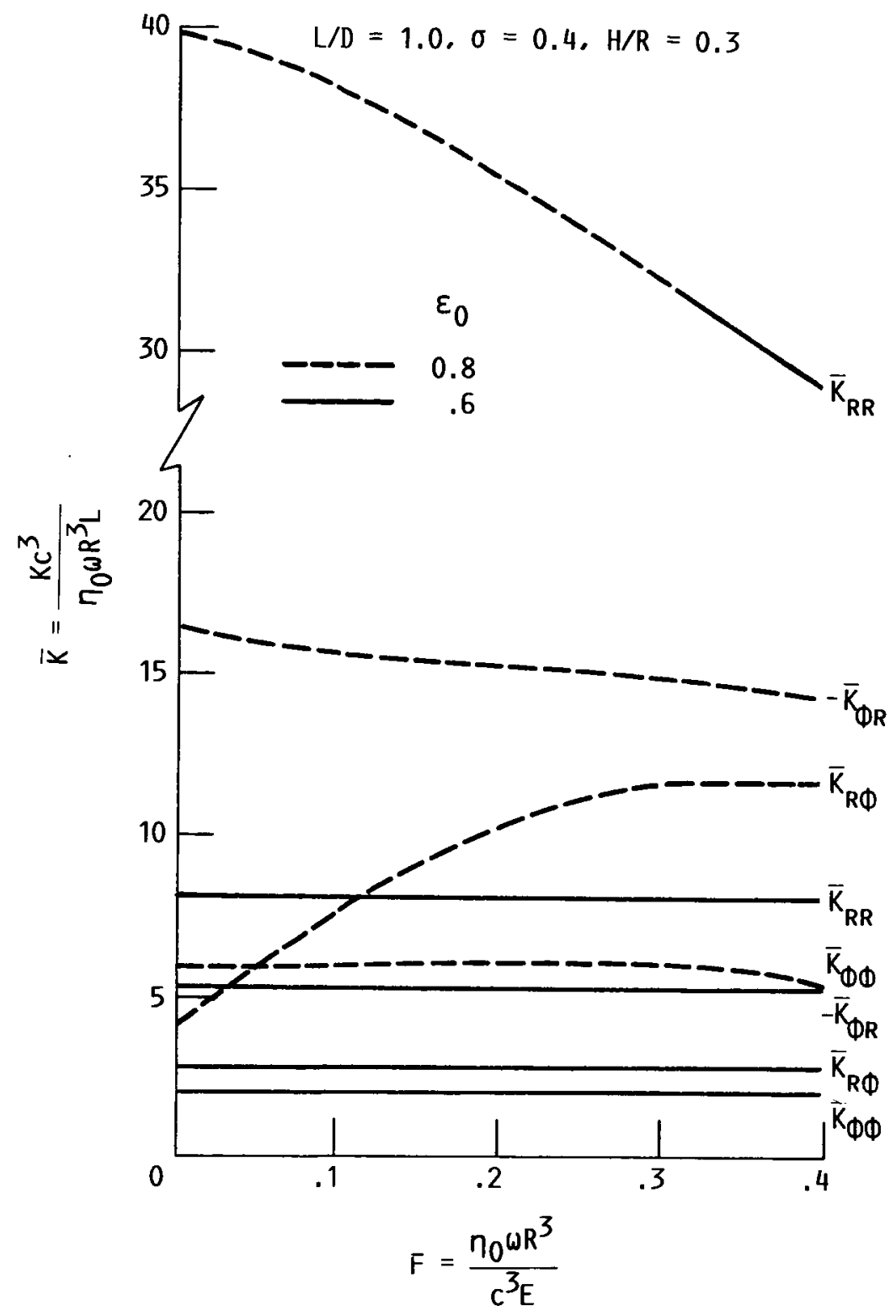

FIGURE 5. - VARIATION OF STIFFNESS WITH ELASTICITY PARAMETER (ISOVISCOUS). 


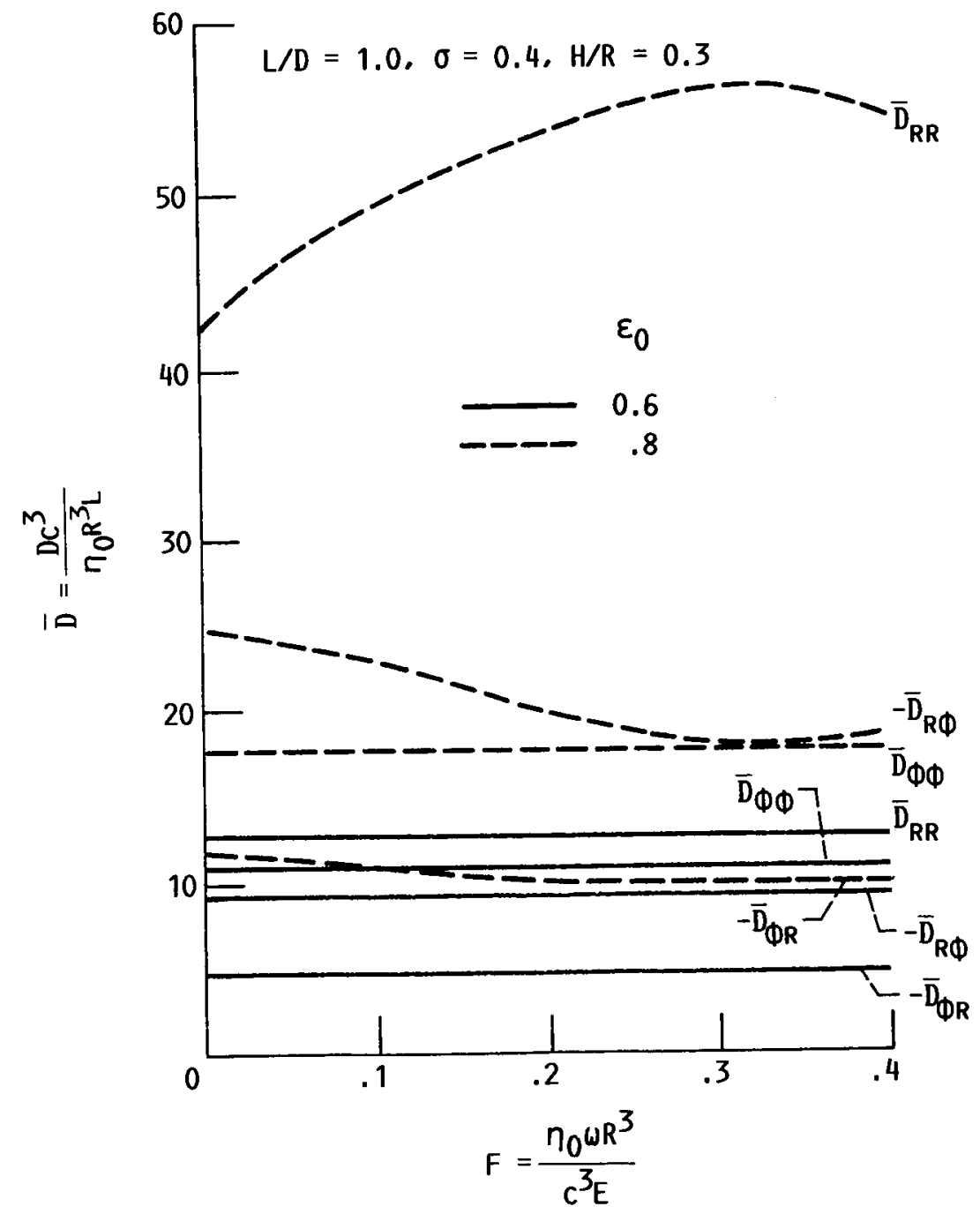

FIGURE 6. - VARIATION OF DAMPING WITH ELASTICITY PARAMETER (ISOVISCOUS). 


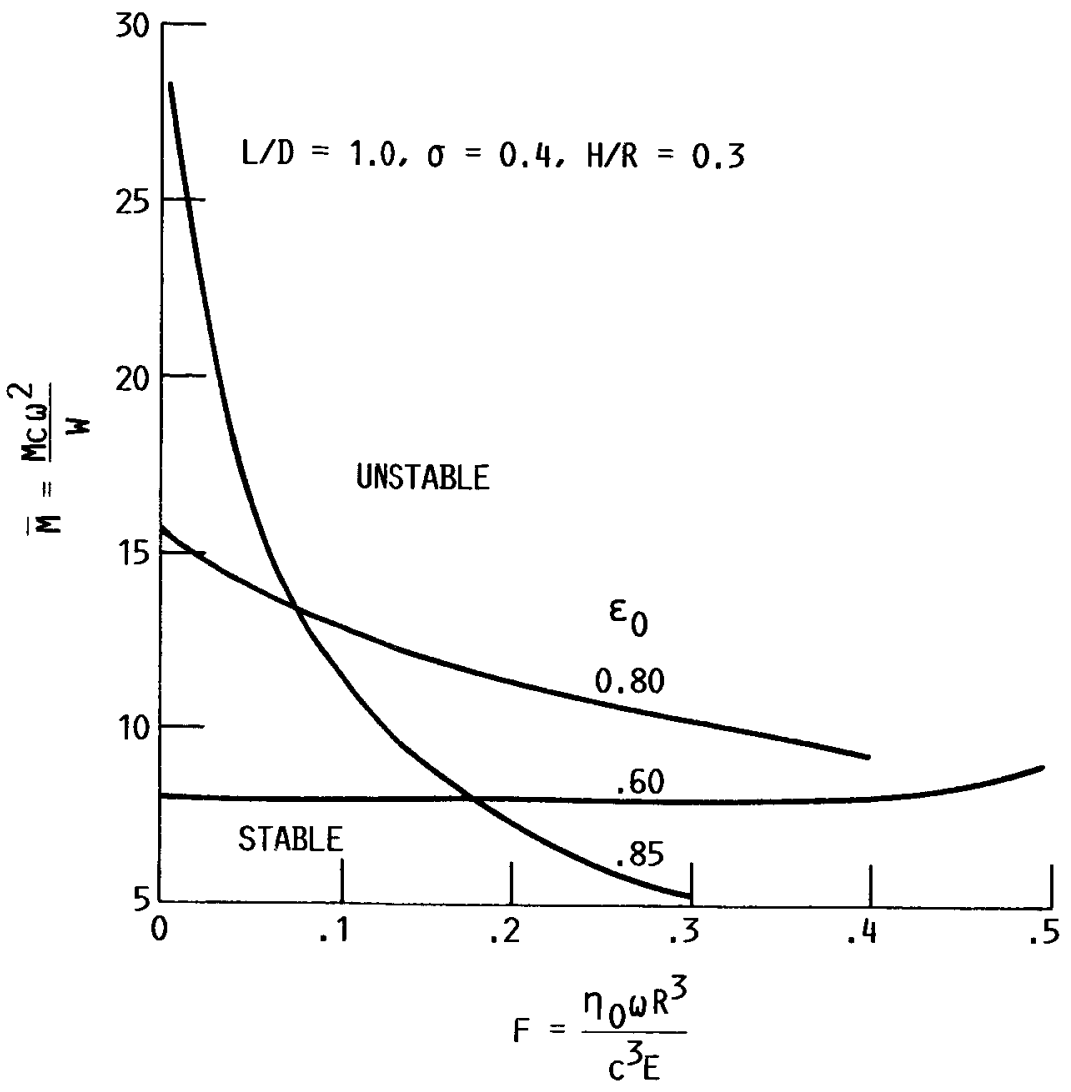

FIGURE 7. - VARIATION OF STABILITY WITH ELASTICITY PARAMETER (ISOVISCOUS).

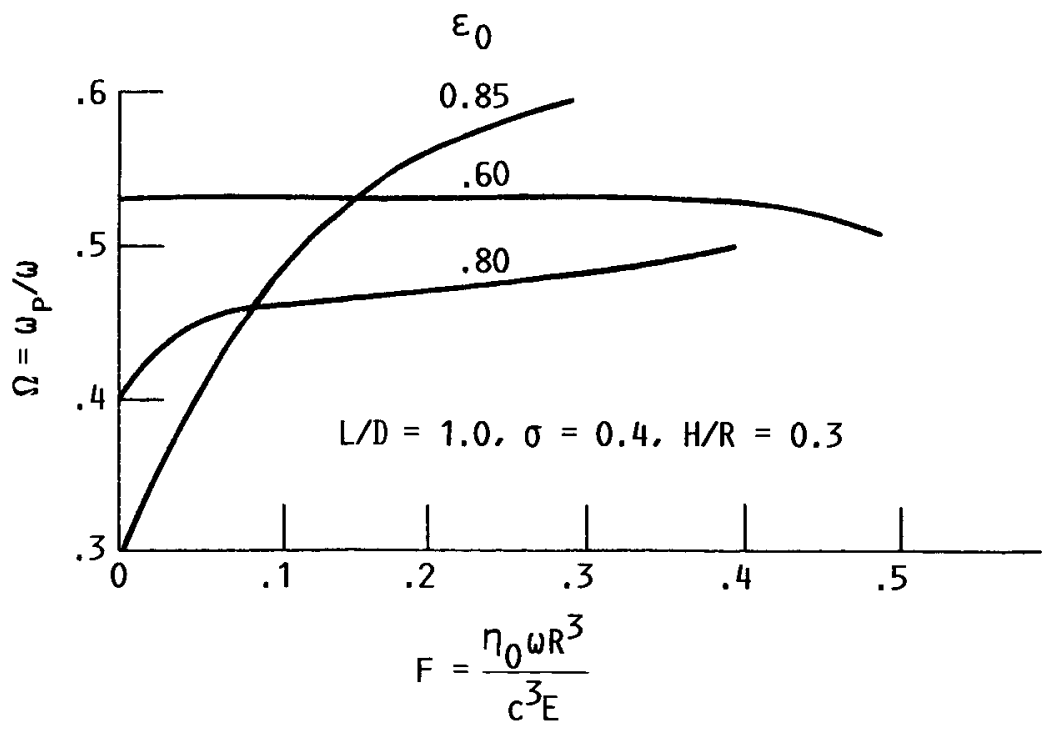

FIGURE 8. - VARIATION OF WHIRL RATIO WITH ELASTICITY PARAMETER (ISOVISCOUS). 


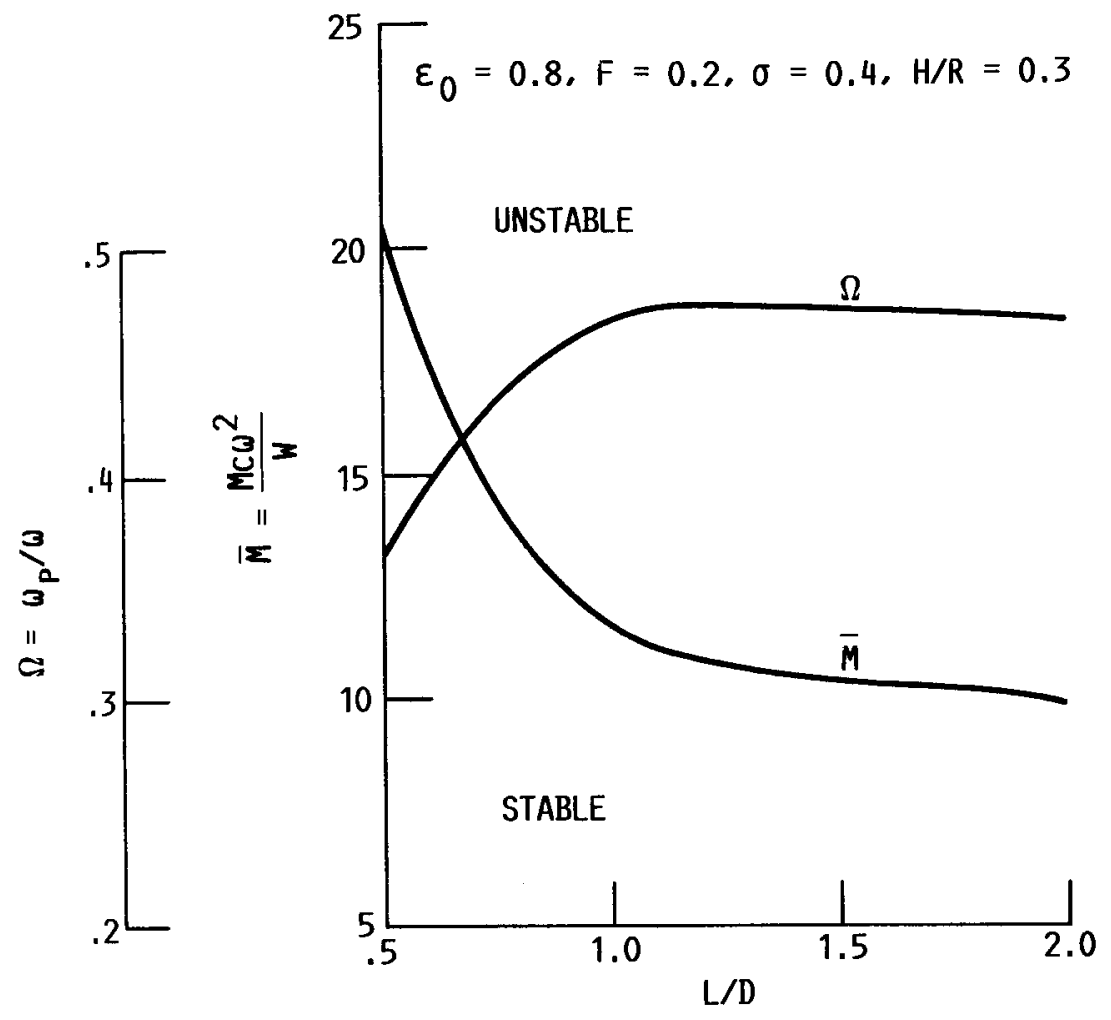

FIGURE 9. - EFFECT OF L/D ON STABILITY AND WHIRL RATIO (ISOVISCOUS).

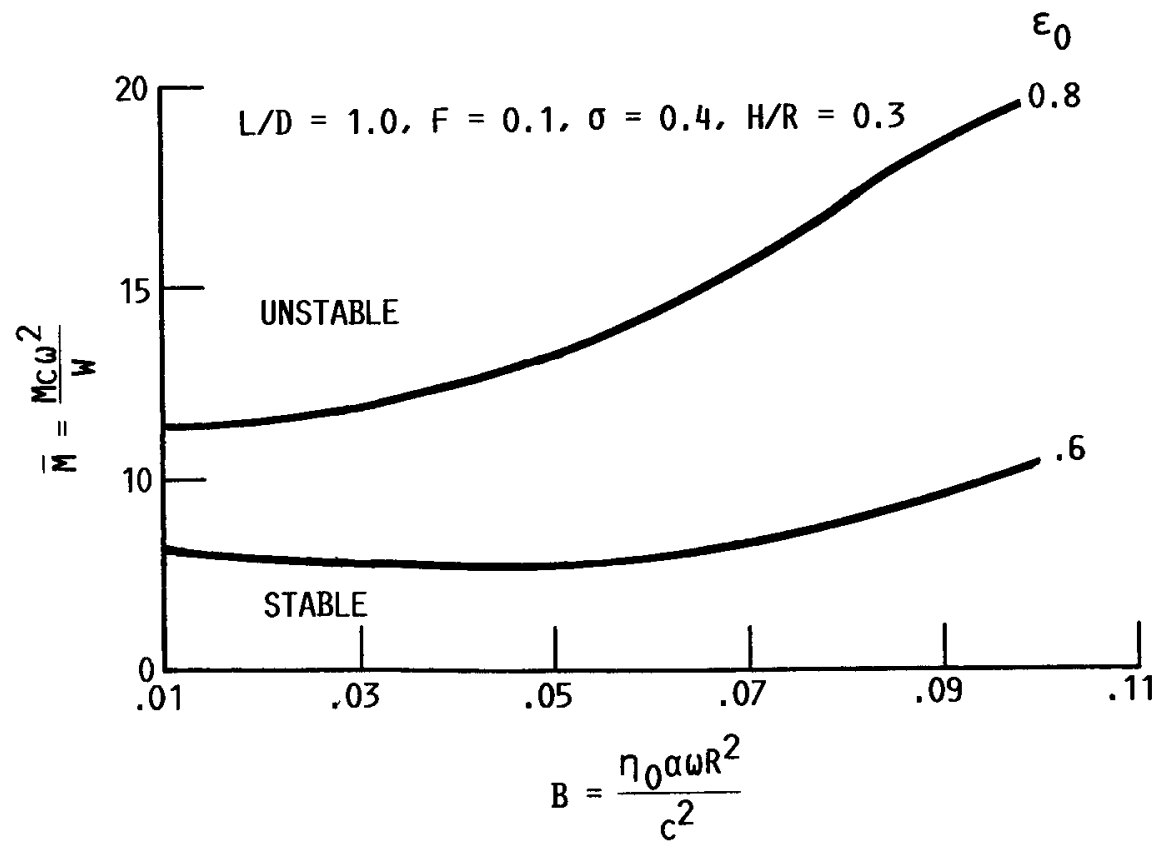

FIGURE 10. - EFFECT OF VISCOSITY OF OIL ON STABILITY. 


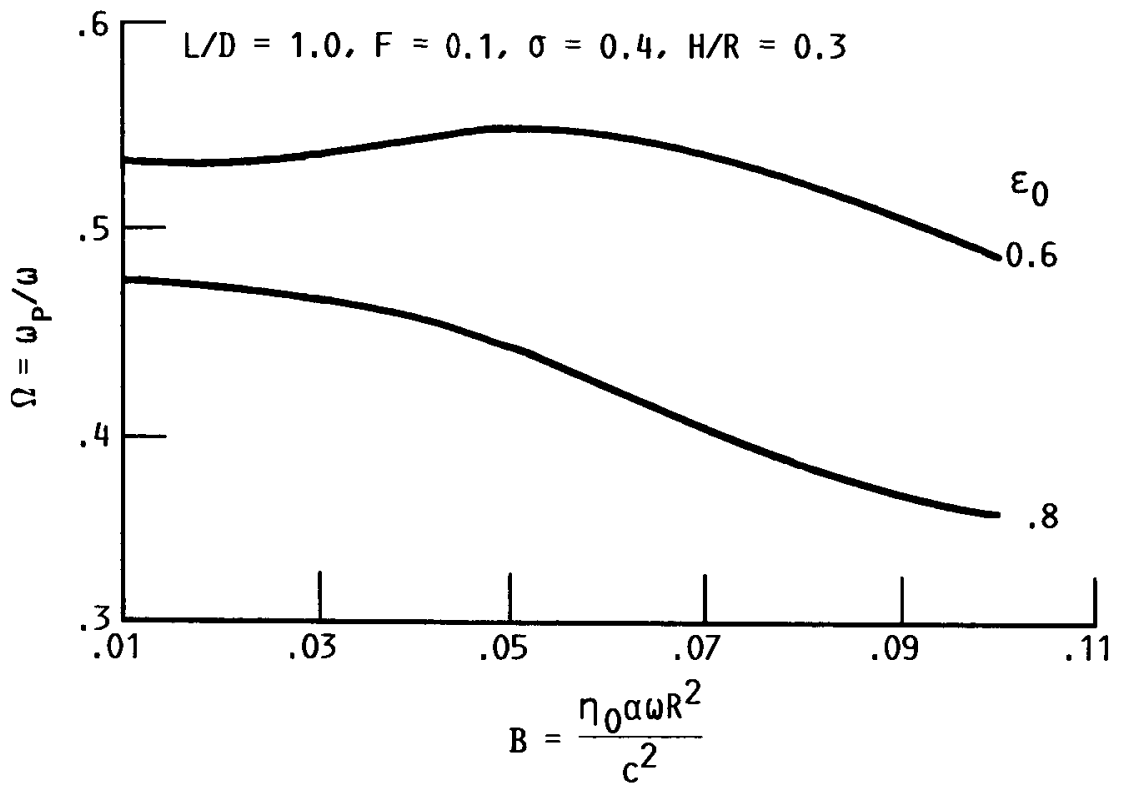

FIGURE 11. - EFFECT OF VISCOSITY OF OIL ON WHIRL RATIO. 


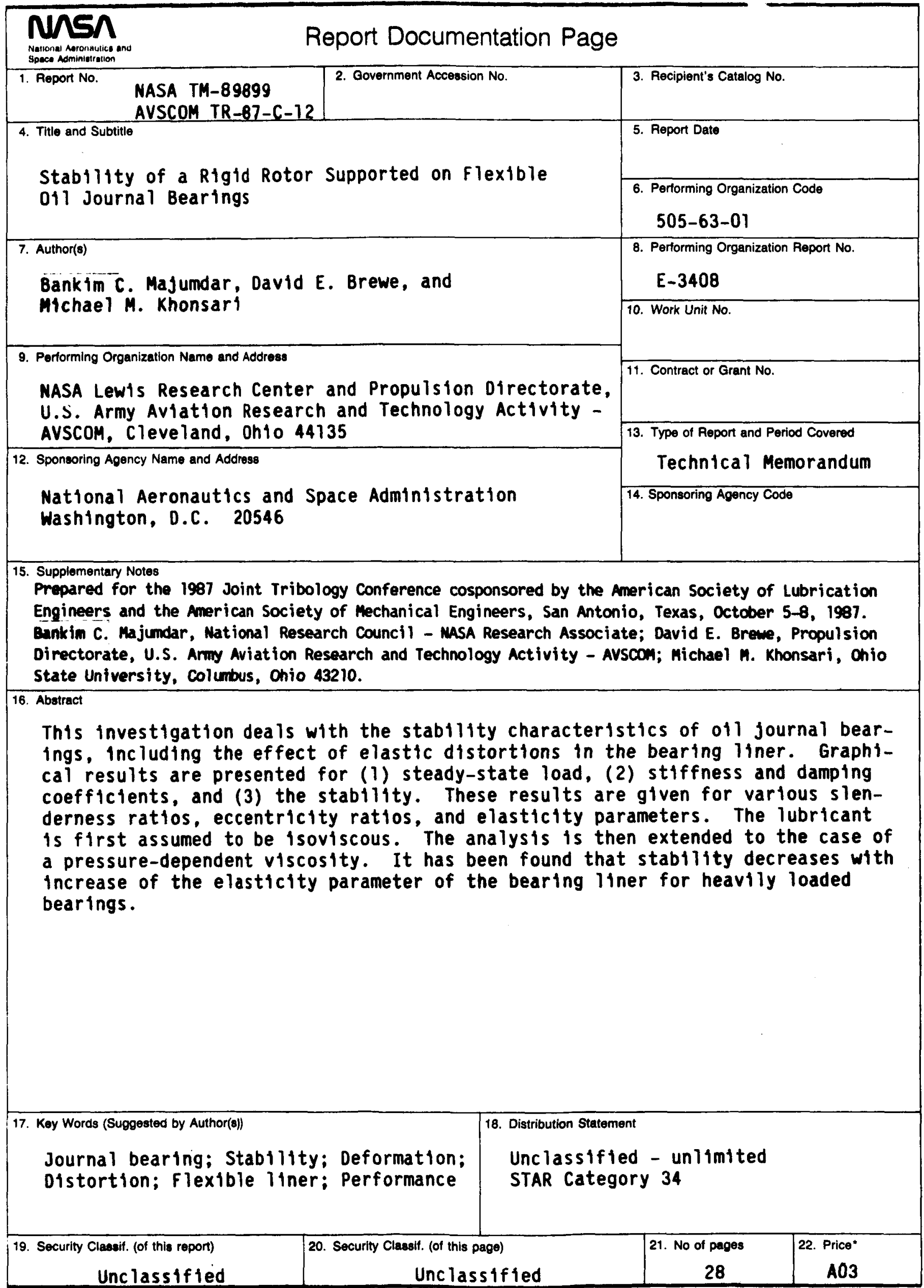

